\title{
Gestalttheorie, Mário Pedrosa y el arte concreto argentino: un capítulo de la historia de la psicologización del estudio de la forma y el color en el arte ${ }^{1}$
}

\author{
María Cecilia Grassi \\ Recebido em setembro de 2020 \\ Aceito em dezembro de 2020
}

\section{RESUMEN}

Mário Pedrosa constituye una figura clave en la historia cultural de Brasil. En este artículo analizamos en clave histórico-crítica su faceta de crítico de arte y su propuesta teórica de articulación de la Gestalttheorie y el arte y su circulación en el arte concreto argentino en las décadas de 1940 y 1950 . Para ello, se analizan dos trabajos fundamentales sobre el tema teniendo en cuenta la centralidad del primero y la función de apéndice del segundo. Se trata de su tesis de 1949 Da natureza afetiva da obra na arte y Forma e personalidade de 1951. Mostramos cómo a partir de los intercambios surgidos entre Brasil y Argentina, sus ideas formaron parte del acervo de los artistas del último país aunque con diferencias en el enfoque del tópico de la forma: mientras Pedrosa reforzaba sus aspectos expresivos, los argentinos justificaban la universalidad en relación a los aspectos objetivos o racionales de la misma. Por último, se sugiere la importancia de analizar la circulación del ideario Pedrosa para situar sus aportes y originalidad en el campo de una historia de la psicología que canoniza la figura de Arnheim y olvida las propuestas surgidas en las periferias.

Palabras-clave: Pedrosa; Arte abstracto; Psicología; Estética.

\section{Gestalttheorie, Mario Pedrosa e a Arte Concreta Argentina: um capítulo na história da psicologização do estudo da forma e da cor na arte}

\section{RESUMO}

Mário Pedrosa é uma figura-chave na história cultural do Brasil. Neste artigo analisamos em um tom histórico-crítico sua faceta como crítico de arte e sua proposta teórica para a articulação da Gestalttheorie e a arte e sua circulação na arte concreta argentina nas décadas de 1940 e 1950. Para tanto, são analisadas duas obras fundamental sobre o assunto levando em conta a centralidade do primeiro e a função de apêndice do segundo. Trata-se de sua tese de 1949 Da natureza afetiva da obra na arte e Forma e personalidade de 1951. Mostramos como a partir das trocas que surgiram entre o Brasil e a Argentina, suas idéias passaram a fazer parte do acervo de artistas do último país, embora com diferenças em a abordagem ao tema da forma: enquanto Pedrosa reforçava seus aspectos expressivos, os argentinos justificavam a universalidade em relação aos aspectos objetivos ou racionais dela. Por fim, sugere-se a importância de analisar a circulação da ideologia de Pedrosa em pesquisas futuras para situar

\footnotetext{
${ }^{1}$ Este artículo se basa en uno de los capítulos de mi tesis titulado "La traducción de la traducción: la Gestalttheorie a través de Grete Stern, los Bauhausbücher y Mário Pedrosa” (Grassi, 2019). A su vez, se enmarca en el Proyecto de Investigación "Psicología y Orden Social: Controversias teórico políticas en las intervenciones de la Psicología en la Argentina (1900-1990)", UNLP dirigido por la Dra. Ana María Talak.
} 
suas contribuições e originalidade no campo de uma história da psicologia que canoniza a figura de Arnheim e esquece as propostas que surgiram nas periferias.

Palavras-chave: Pedrosa; Arte abstrata; Psicologia; Estética.

\title{
Gestalttheorie, Mário Pedrosa and Argentinean Concrete Art: A Chapter in the History of the Psychologization of the Study of Form and Color in Art
}

\begin{abstract}
Mário Pedrosa is a key figure in Brazilian cultural history. In this article we analyze in a historicalcritical key his facet as an art critic and his theoretical proposal of articulation of Gestalttheorie and art and its circulation in Argentinean Concrete art in the 1940s and 1950s. For this, two fundamental works on the subject are analyzed taking into account the centrality of the former and the function of appendix of the latter. These are his thesis from 1949 Da natureza afetiva da obra na arte and Forma e personalidade from 1951. Based on the exchanges that emerged between Brazil and Argentina, we show how his ideas became part of the document collection of artists from the last country, although with differences in the approach to the topic of form: while Pedrosa reinforced its expressive aspects, Argentinean artists justified universality in relation to the objective or rational aspects of it. Finally, as a suggestion for future research, we point out the importance of analyzing the circulation of the Pedrosa ideology to place his contributions and originality in the field of a history of psychology, which in general canonizes the figure of Arnheim and forgets the proposals that emerged in the peripheries.
\end{abstract}

Key words: Pedrosa; Abstract art; Psychology; Aesthetics.

\section{Introducción}

A principios del siglo XX, el arte abstracto de movimientos como el Constructivismo ruso, el Neoplasticismo holandés o la Bauhaus recurrió a la psicología para justificar sus ideas y experimentar en las obras de arte. En esos años se dio en el arte abstracto un proceso que hemos denominado psicologización del estudio de la forma y el color, que supuso la apelación a discursos psicológicos (en especial de la Gestalttheorie) para la experimentación y la fundamentación de los programas abstractos que cuestionaban la hegemonía del arte representativo. En Buenos Aires (Argentina) durante las décadas de 1940 y 1950, un grupo de jóvenes artistas crearon diferentes movimientos de arte abstracto como la Asociación Arte Concreto Invención [Asociación Arte ConcretoInvención o AACI], Madí o Perceptismo. Estos movimientos privilegiaron los aspectos racionales y objetivos de la obra de arte e hicieron que la forma y el color fueran los elementos principales de la pintura. Junto a otros discursos científicos como el de la física, la Gestalttheorie tuvo en ellos un lugar específico en la trama argumentativa que 
justificaba tanto las prácticas artísticas de sus integrantes como sus elaboraciones teóricas. En una investigación previa hemos calificado como "latente" a la presencia de estos discursos psicológicos en el arte concreto argentino debido a la forma particular de inclusión en los textos, manifiestos y demás escritos realizados por los artistas de los diferentes movimientos. Esta latencia que se refleja en la ausencia de referencias bibliográficas o en las menciones de ideas o conceptos pero no de sus autores, daría cuenta de regímenes estéticos de circulación epistémica específicos que muestran la presencia de la Gestalttheorie a la vez que ocultan las fuentes o los autores a los que se apela (GRASSI, 2019).

Enfocados en las vías de recepción y de traducción por fuera del circuito académico que se establecieron entre la Gestalttheorie y el arte abstracto argentino durante las décadas de 1940 y 1950, en este artículo abordaremos los contactos de los artistas concretos argentinos con Mario Pedrosa en los años ' 50 y cuáles fueron las ideas de Pedrosa que pasaron a formar parte de la retórica de los primeros. De las múltiples facetas de Pedrosa, aquí consideraremos su rol como crítico de arte y en especial sus desarrollos sobre los vínculos entre arte y Gestalttheorie.

En 1951, Tomás Maldonado y Lidy Prati, ambos artistas abstractos argentinos, viajaron a Brasil y estuvieron en contacto con Pedrosa y con artistas abstractos brasileños como Geraldo De Barros y Waldemar Cordeiro. En ese encuentro y en sucesivos intercambios (que incluyeron cartas y publicaciones cruzadas) (GARCÍA, 2011) es que situamos el aporte de Pedrosa a las búsquedas argentinas ligadas a la Gestalttheorie en artistas como Prati, Alfredo Hlito o Raúl Lozza.

El material analizado en clave histórico-crítica a raíz de esos intercambios, consiste dos escritos de Pedrosa sobre el tema para mostrar la originalidad y la solidez de un planteo que articuló Gestalttheorie y arte y que en la historia de la psicología es un tópico aún poco indagado. Se trata, en orden cronológico, de Da natureza afetiva da forma na obra de arte (1949) y Forma e personalidade (1951). Aunque otras psicologías hayan sido consideradas por Pedrosa, analizaremos Da natureza afetiva... como texto fuente principal y Forma e personalidade como complemento en función de las continuidades en los temas de la Gestalttheorie en ambos.

Da natureza afetiva da forma na obra de arte fue la tesis que defendió en el 
concurso de la cátedra de Historia del Arte y Estética de la facultad Nacional de Arquitectura de Río de Janeiro en 1949 en donde articulaba las leyes de la percepción con la experiencia estética a través del estudio de la forma. Forma e personalidade fue un libro publicado por el Ministerio de Educación y Salud en 1951 y si bien allí considera algunos desarrollos de la Gestalttheorie, es un texto en el que se advierte una mayor atención a otros desarrollos como los de Heinz Werner sobre la percepción fisionómica y las ideas de Hans Prinzhorn (CABANAS, 2018)².

Otra razón para su consideración en conjunto es que ambos textos serían publicados en 1979 en su libro Arte, Forma e Personalidade a pedido del propio Pedrosa. Otília Beatriz Fiori Arantes (1995) recuerda que él consideraba este ensayo como un escrito complementario a su tesis (Da natureza afetiva da forma na obra de arte), prácticamente como un apéndice.

Durante las décadas de 1940 y 1950, en el contexto de una serie de intercambios culturales y relaciones interpersonales establecidas en diversos viajes (y continuadas a través de correspondencia), Argentina y Brasil contaron con instituciones, artistas, críticos y publicaciones que fueron agentes activos en la circulación del arte abstracto en la región. Este circuito implicó también la circulación de los usos de los discursos científicos en el arte -entre ellos, la psicología- que las diferentes propuestas hacían; de ahí, la importancia de Pedrosa para pensar en estos cruces.

Por el lado institucional, podemos mencionar el Instituto de Arte Moderno de Buenos Aires y el Museu de Arte Moderna de San Pablo que compartieron en 1949 la muestra Do Figurativismo ao Abstracionismo3. Esta muestra que constituía un panorama del arte no figurativo europeo (mayormente francés), inauguró ambos

\footnotetext{
2 Cabanas (2018) considera que en 1951 hay un "giro fisionómico" en el pensamiento de Pedrosa en cuanto a la comprensión de la forma y la expresión. Nosotros entendemos que en realidad el tema de la fisionomía está presente desde 1949 cuando Pedrosa analiza los desarrollos de Koffka sobre las cualidades terciarias o fisionómicas.

3 El catálogo de esta muestra fue escrito por Léon Degand, director artístico del MAM-SP quien, como parte del circuito regional en ciernes, publicó un artículo en la revista cultural porteña Saber vivir. En "Breve psicología del arte abstracto" (1949) planteaba el condicionamiento ambiental del gusto estético y la necesidad de desarrollar una psicología del lenguaje plástico. Degand sostenía que la emoción artística era un reflejo condicionado. La educación recibida por parte de los espectadores respecto del gusto estético explicaba la incomprensión o la prohibición de la emoción frente a una obra de arte abstracta (Grassi, 2018).
} 
espacios aunque en escenas culturales diferentes. En Brasil, el arte abstracto no era bien recibido en algunos círculos y algunos sectores de la crítica. No obstante, Pedrosa constituía una excepción a ese clima de adversidad ya que apoyaba las propuestas no figurativas. En Argentina, la muestra se denominó El Arte Abstracto, inauguró en Buenos Aires el Instituto de Arte Moderno creado por Marcelo de Ridder y fue exitosa en cuanto a convocatoria y a la crítica que, en términos generales, destacó la propuesta (GARCÍA, 2011).

En cuanto al circuito de publicaciones, podemos hablar de textos o reportajes publicados por artistas argentinos como Maldonado en periódicos de Brasil y textos publicados por críticos del ámbito brasileño en la Argentina. De estos últimos, nos resultan de particular importancia dos trabajos de Pedrosa publicados en revistas culturales argentinas de la época en los que hallamos algunas ideas referidas a la noción de totalidad y al papel de la ciencia en el arte que poseen cierto aire de familia con las ideas aparecidas en Forma e personalidade y Da natureza afetiva. Se trata de los artículos "Calder y la música de los ritmos visuales”, aparecido en Ver y Estimar en el año 1953 y "Las relaciones entre la ciencia y el arte” publicado en la revista nueva visión en $1955^{4}$.

En el primero, Pedrosa (1953) analiza los móviles de Calder a propósito de una muestra reciente y destaca el esfuerzo de unidad en las creaciones del artista, quien logra con sus móviles superar la división entre artes espaciales y de sucesión en el tiempo. Describe a los móviles como formas totalmente libres, sin referencia alguna a objetos de la realidad y refuerza el carácter de síntesis final de fines, materiales y medios en cada uno:

La unidad visual y espacial de estos objetos se revela en la trama y contorno de líneas o planos externos y en la fuerza, convincente y funcional de los materiales utilizados. Lo que mantiene la unión y cohesión de todo ese grupo artístico es el poder de afirmación de esa unidad total en fuerte contraste con el espacio circundante (PEDROSA, 1953, p. 18, el destacado es nuestro).

Creemos que esta noción de unidad total está en sintonía con la idea de gestalt

\footnotetext{
${ }^{4}$ Este texto titulado en portugués "As relações entre a ciência e a arte" fue escrito en París y presentado en el IV Congreso de AICA en Dublin en julio de 1953.
} 
o totalidad planteada por la Gestalttheorie que a su vez está enmarcada en el holismo que primaba en Alemania cuando esta psicología comenzó a desarrollarse y que fue clave en los desarrollos de Pedrosa en relación al arte. Además, podría interpretarse la relación del móvil como unidad total en relación con un espacio circundante diferenciado como una forma de la relación figura-fondo que es propia de la teoría y que Pedrosa analiza detalladamente en 1949.

Otro de los textos que permiten reconstruir el circuito de difusión de las ideas de Pedrosa en la Argentina, y más concretamente en el ámbito porteño, es el artículo aparecido en la revista dirigida por Tomás Maldonado, nueva visón. En este caso, se trata de un texto teórico en donde el crítico brasileño analiza las relaciones entre la ciencia y el arte. Allí describe cómo ha sido el proceso de autonomización de cada una de estas actividades sociales a lo largo de la historia. A su juicio, la ciencia como actividad autónoma es una conquista más vieja en comparación con la reciente situación del arte. Más concretamente, el arte abstracto corona el largo proceso del fenómeno artístico hacia la autonomía, al prescindir del objeto o al utilizar solamente sus proyecciones en el espacio. Al convertirse en un fin en sí mismo, Pedrosa (1955) sugiere que el arte ha logrado librarse de sus servidumbres seculares y se ha independizado de la realidad. El movimiento del arte moderno implicaba la reconciliación del artista con la cosa sensible y el reencuentro con las viejas bases intuitivas que por ejemplo, en la filosofía, habían desaparecido por la dominación del neokantismo y el positivismo.

En este trabajo, Pedrosa era sumamente claro con respecto a la relación de la psicología y en especial la Gestalttheorie, con el arte moderno y destacaba la coincidencia en los desarrollos de ambos al volver su atención nuevamente hacia el papel jugado por la intuición y la percepción directa inmediata:

En el plano de la psicología, el asociacionismo hacía imitaciones pueriles de los métodos de laboratorio del siglo 19. Las psicologías de profundidad y las psicologías de estructura hicieron su entrada en la ciudadela científica, en el mismo momento y con el mismo sentido histórico que el postimpresionismo, el fauvismo y el expresionismo. La última etapa del arte llamado moderno se inicia después de la recuperación intuicionista de los movimientos precedentes. El arte se coloca ahora en una posición diferente de la vieja concepción de la naturaleza y de la realidad, aunque simétrica con respecto a la de la ciencia (PEDROSA, 1955, p. 15). 
A continuación, era el turno de los argumentos a favor de plantear al arte como una forma especial de conocimiento o como un pensamiento articulado intelectual y Pedrosa apelaba a los desarrollos de Sussanne Langer sobre los simbolismos no discursivos (como el arte) y su hipótesis, apoyada en las concepciones intuicionistas de la Gestalttheorie, de que la razón se basaría en primera instancia en la organización psicofísica de la percepción (PEDROSA, 1955).

Queda expuesto en el análisis de los textos de 1953 y 1955 que esta corriente de la psicología alemana era para Pedrosa un instrumento fértil para interpretar las obras de arte como en el caso de Calder y para analizar el devenir del arte en comparación con la ciencia y sus posibles vinculaciones. Ambos fueron en esos años, material de lectura de los artistas argentinos (además de otros lectores) quienes retomaron algunos temas planteados por Pedrosa en sus propios textos o en sus obras. No obstante, es necesario considerar que debido a la forma de circulación de las ideas en el ámbito artístico (muy distinta a la del ámbito académico, por ejemplo, con su regulación sobre las referencias bibliográficas) la presencia de la Gestalttheorie se advierte con claridad en los argentinos aunque resulta harto dificultoso situar con precisión de qué autores o textos se toman algunas ideas. En todo caso, aquí solo nos interesa cómo Pedrosa se incorporó a la lista de autores que formaron parte del corpus que permite hablar de la psicología de la Gestalt como corriente clave en el estudio de la forma y el color en el arte abstracto argentino y brasileño.

Si repasamos algunas cuestiones propias de los contextos históricos de ambos países, podemos decir que mientras en Brasil, durante esos años, el Estado y la burguesía adhirieron a las propuestas modernistas, en la Argentina no sucedió lo mismo a nivel estatal, en particular durante los comienzos del arte concreto, momento coincidente con los primeros años de la primera presidencia de Juan D. Perón. En el caso de Brasil, a fines de la década de 1940, estado y burguesía llevaron adelante un programa moderno de gestión cultural artística que aspiraba a disputar la supremacía cultural argentina de esa época. Como parte de las acciones del programa, entre 1947 y 1949 se abrieron tres museos de arte que fueron determinantes en el desarrollo cultural del país: el Museu de Arte Moderna de San Pablo (MAM-SP), el Museu de Arte Moderna 
de Río de Janeiro (MAM-RJ) y el Museu de Arte de São Paulo (MASP). Otro hito en esta disputa por la hegemonía cultural, fue la creación de la Bienal de São Paulo en 1951, cuyo primer premio fue para una escultura constructivista del suizo Max Bill. (GARCÍA, 2011).

En este marco de renovación e intercambios culturales en donde lo abstracto se había transformado en sinónimo de moderno, se produjo un encuentro que posibilitó una nueva vía de acercamiento de los artistas concretos porteños con la Gestalttheorie 5 . Como ya mencionamos al comienzo, nos referimos concretamente al crítico de arte Mário Pedrosa y la visita que le hicieron Tomás Maldonado ${ }^{6}$ y Lidy Prati en Río de Janeiro en el año 1951. En esa ocasión, Pedrosa le obsequió al matrimonio el libro Forma e personalidade (GARCÍA, 25 de agosto de 2009). A partir de ese entonces, quedaron establecidas vías de intercambio que, como analizamos antes, derivaron en publicaciones de Pedrosa en revistas argentinas y también (aunque no nos centremos en ellas aquí) comunicaciones por correspondencia con artistas y con críticos argentinos como Jorge Romero Brest.

Pedrosa apoyó e impulsó la abstracción geométrica y el neoconcretismo en Brasil. Sus escritos devinieron referencias teóricas para artistas miembros del Grupo Frente (de Río de Janeiro), como Lygia Clark (1920-1988), Ivan Serpa (1923-1973), Abraham Palatnik (1928-), Lygia Pape (1927-2004) ${ }^{7}$ y del Grupo Ruptura ${ }^{8}$ de San Pablo (véase por ejemplo el contacto De Barros- Pedrosa en García, 2011). Pedrosa

\footnotetext{
${ }^{5}$ En un trabajo anterior fijamos como otras vías de circulación y recepción de la Gestalttheorie en el ámbito artístico argentino el encuentro con Grete Stern y los Bauhausbücher (Grassi, 2019).

${ }^{6}$ Tomás Maldonado había sido invitado e dar un curso de enseñanza musical y artística organizado en Teresópolis por el músico dodecafonista alemán Hans-Joachim Koellreutter (García, 2011). Para profundizar en los contactos entre los concretos argentinos y este músico puede consultarse Rossi, C. (2007) "Vanguardia concreta rioplatense: acerca del arte concreto y la música" Recuperado de: http://icaadocs.mfah.org/icaadocs/Portals/o/WorkingPapers/No1/Cristina\%2oRossi.pdf)

${ }^{7}$ Frente (1954-56) fue un grupo abstracto carioca que articuló la experimentación con los materiales y la función social del arte. No consideraban al objeto artístico como el resultado de un ejercicio racional, cuya ejecución debía ser previamente guiada por leyes claras e inteligibles, preferentemente vinculadas a la matemática. En ese sentido puede decirse que privilegiaban la libertad de creación. Si bien se los vinculaba con el arte concreto, no era el único estilo que practicaban.

${ }^{8}$ Ruptura fue un grupo de abstracción constructiva paulista creado en 1952, adherían a la abstracción constructiva y a la reelaboración del neoplasticismo europeo realizada por Bill. Consideraban al arte como un medio de conocimiento regido por principios objetivos y a la obra como una realidad en sí misma, no representacional. Algunos de sus integrantes fueron Luis Sacilotto (1924-2003), Geraldo De Barros (1923-1998), Waldemar Cordeiro (1925-1973) y Lothar Charoux (1912-1987).
} 
reivindicaba un lugar propio para el arte brasileño y pretendía ponerlo en diálogo con el panorama internacional. Su visión desjerarquizada del arte se basaba en la idea de que no existía un estilo o un lenguaje superior a otro: simplemente era necesario situar las creaciones artísticas en el contexto histórico de origen para comprender sus condiciones de producción y de circulación (PEDROSA, 2017).

Pedrosa desafiaba la clásica oposición en el arte moderno entre la defensa de la diversidad de opciones estéticas y la lucha ideológica para defender una propuesta estética por encima del resto. Él constituía una excepción a estos planteos típicos de la modernidad (con los que los concretos argentinos estaban muy identificados), ya que si bien apoyó a los primeros artistas abstractos de Río de Janeiro nunca cayó en la defensa acérrima de un lenguaje por encima de otro. Este dato no resulta menor porque su filiación política -era marxista y trotskista- nunca fue un obstáculo para defender esta postura pluralista en el arte. De hecho, siempre criticó que la URSS apoyara exclusivamente el realismo socialista como el único arte revolucionario. Coherente con su posición, el apoyo que Pedrosa brindó a la nueva generación de artistas abstractos de los años '5o del Grupo Frente no fue exclusivo ni incondicional. Los integrantes del grupo reconocían su influencia por dos vías: los textos de Pedrosa sobre sus obras rescataban el potencial de ese lenguaje artístico y significaban un reconocimiento en el medio de muchas críticas. Y además, Pedrosa constituía una fuente de información sobre las teorías del arte e incluso muchos de esos artistas reconocían que las tesis de Pedrosa sobre la Gestalttheorie habían influido decisivamente en su obra y en sus ideas (por ejemplo Clark, Serpa y Oiticica) (PÉREZBARREIRO, 2017).

En 1925 Pedrosa había ingresado al Partido Comunista y en 1927 había sido enviado a la Escuela Leninista de Moscú. Cuando emprendió ese viaje, llegó primero a Berlín y por razones de salud no pudo arribar al destino final. Instalado allí entre 1927 y 1929, tomó contacto en la Universidad de Berlín con los desarrollos de la Gestalttheorie gracias a su incursión en la Sociología y la Filosofía (ARANTES, 1995; GARCÍA, 2011). Este acercamiento permitió a Pedrosa profundizar en el estudio subjetivo de los procesos de la percepción y de la creación artística, y descubrir que el potencial revolucionario del arte radicaba en el hecho de ser un fenómeno subjetivo individual y 
no un mero síntoma de la lucha de clases. Esta última concepción, ligada al marxismo ortodoxo aparecía expuesta claramente en su texto "Las tendencias sociales del arte y Käthe Kollwitz" (1933). Allí destacaba la lealtad a su clase de la artista expresionista alemana y cómo a través de la obra se lograba que el espectador comprendiera la experiencia de clase transmitida en ella y se conmoviera hasta el punto de estar dispuesto a luchar (Pérez-Barreiro, 2017). Arantes (1995) considera este escrito como el primer ensayo científico sobre las artes modernas en donde el crítico brasileño, atento a lo político, realizaba una defensa del arte proletario y un ataque al arte "moderno" entendido como los juegos de una casta privilegiada.

Con el paso del tiempo, la posición de Pedrosa cambió al punto de renunciar a la exigencia planteada en el texto de Kollwitz y sostener que el artista estaba al margen del sistema de producción (o sea, era independiente del capitalismo o del comunismo) y que por lo tanto, no debía representar los intereses de su clase en su obra artística (PÉREZ-BARREIRO, 2017). Además de esta modificación en su visión de las relaciones entre arte y compromiso político, en la década de 1940 adhirió a la causa del arte moderno luego de que se exiliara unos años en Estados Unidos (ARANTES, 1995). Instalado en Brasil, escribió los textos que analizaremos en los siguientes apartados para mostrar cómo sus desarrollos forman parte de las vías de acceso a la Gestalttheorie de los artistas argentinos aún cuando la cuestión de la citabilidad en el mundo no académico sea un obstáculo para determinar con exactitud los autores y los textos de los que tomaban las ideas que fundamentaban sus propuestas o con las que directamente discutían.

\section{Sobre Forma e personalidade}

Pedrosa consideraba que el arte era el resultado de una profunda necesidad humana de comunicación y de un diálogo entre las formas y la percepción. La experimentación formal del arte abstracto ponía sobre el tapete el problema de la percepción y la manera de aprehender por parte del espectador una obra sin otra referencia que la forma misma. Respecto a este tema, la Gestalttheorie se presentaba como un instrumento útil para entender el proceso artístico y la creación de imágenes 
visuales 9 . El arte abstracto no era un ejercicio de pura racionalidad, sino que debía considerarse dentro de la esfera del arte que, para Pedrosa, era un sistema de significación más complejo que la pura razón (PÉREZ-BARREIRO, 2017).

En esa suerte de apéndice a la tesis de 1949 que conformó Forma e personalidade (1951), el debate giraba en torno a los sustratos emocionales del placer estético. Para Pedrosa, quien retomaba esta idea de la intervención del crítico inglés Roger Fry en la Sociedad de Psicoanálisis de Londres, el fenómeno artístico escapaba a la pura interpretación psicoanalítica (sea freudiana o jungiana) porque no daba con los auténticos impulsos estéticos que impulsan al artista. Cuando se percibía una obra, la tarea de la psicología era desentrañar las fuentes del placer obtenido en el reconocimiento de un orden y de cierto tipo de relaciones en un sistema determinado. Para Fry existía un tono o cualidad afectiva que no serían de carácter inmediato. El arte tendría acceso a algo mucho más profundo en el ser humano, algo así como el sustrato de todos los colores emotivos de la vida y algo más allá de cualquier experiencia $\operatorname{cotidiana}^{10}$.

Por lo tanto, para develar el secreto de la emoción estética indiscutiblemente había que sopesar primero las cualidades plásticas y formales de una obra. Cuando el psicoanálisis interpretaba la obra de arte como manifestación de un deseo reprimido y deducía que el mecanismo activo era el mismo que en la formación de un síntoma, no distinguía, no aislaba, ni explicaba en absoluto, según Fry, la obra misma como objeto de arte, su razón de ser o la fuente de las emociones que despertaba sobre los que la percibían.

En este punto puede establecerse un acuerdo entre Fry y Pedrosa (1995 [1951]), dado que para ambos la obra de arte era una cosa en sí misma, su forma tenía un sentido propio y la contemplación de la misma provocaba en ciertas personas una emoción espacial que no dependía de la asociación de esas formas con cualquier otra

\footnotetext{
9 Cabe recordar que la Gestalttheorie no es la única teoría psicológica utilizada por Pedrosa en sus escritos. Los desarrollos sobre el inconsciente y en particular la obra de Henry Wallon La conscience et la vie Subconsciente, París, PUF, 1942, fueron incorporados y están claramente expuestos en la conferencia pronunciada en 1947 a propósito del cierre de una exposición de pintura de los internos organizada por el Centro Psiquiátrico Nacional en Río de Janeiro, en el salón del Ministerio de Educación y Salud, entre el 21 de febrero y el 31 de marzo de 1947.

1o Aquí Pedrosa realiza una comparación con el concepto de Jung de imágenes o experiencias arquetípicas. Dado que excede los objetivos de nuestro trabajo no profundizaremos en ello.
} 
cosa (como sucedería con los símbolos).

Ahora bien, el crítico brasileño que en este texto se centraba en las manifestaciones primitivas del arte, no acordaba totalmente con el formalismo extremo de Fry. Pedrosa esbozaba una teoría que valorizaba la forma pero que también enfatizaba la subjetividad; allí, la Gestalttheorie y otras teorías se transformaban en el recurso adecuado para saldar algunas preguntas.

A partir de desarrollos como los de Jeanne Hersch, Minkowska, Heinz Werner y el médico psiquiatra Prinzhorn, Pedrosa adoptaba una posición que Arantes (1995) señala, es muy similar a la del poeta surrealista André Breton en 1941 en Estados Unidos. Al hacer un balance del surrealismo y considerar la psicología de la época, en especial la Gestalttheorie, Breton afirmaba que entre las cualidades sensibles y las formales no existía distinción y que el automatismo gráfico obedecía a tensiones individuales profundas, al mismo tiempo que era capaz de satisfacer plenamente la vista o el oído por su unidad rítmica. En un trabajo reciente, Cabanas (2018) señala que en Forma e personalidade se da un alejamiento de los autores de la Gestalttheorie por parte de Pedrosa y un acercamiento a Werner y sus teorías fisionómicas y a Prinzhorn por su trabajo en el arte con pacientes psiquiátricos. Si bien es cierto que para explicar el tema de la expresión acude a estos autores en 1951, consideramos que, a la luz de los planteos en Da naturaza afetiva..., Pedrosa abordaba allí ese mismo tema a partir de la noción de cualidades terciarias de Koffka; por lo tanto, la incorporación de Werner y Prinzhorn puede ser entendida como una manera de ampliar los desarrollos de la tesis de 1949 y no necesariamente, un alejamiento.

En resumen, en Forma e personalidade, Pedrosa intentaba conciliar los impulsos inconscientes o de afirmación y los de ordenamiento formal. Es decir, pretendía contemplar tanto a la forma como a la personalidad en el proceso creativo y sus resultados, pero con una visión del inconsciente (claramente opuesta a la del psicoanálisis) como instancia que no escapaba a la regulación de las leyes de la percepción (PEDROSA, 1995[1951]). De todas formas, su función de apéndice exige analizar en detalle los núcleos principales de la tesis de Pedrosa Da natureza afetiva... para destacar su aporte innovador para la comprensión y explicación del arte y señalar algunas convergencias y diferencias respecto a las posiciones abstractas brasileñas y 
argentinas.

\section{Da natureza afetiva da forma na obra de arte: la propuesta teórica y metodológica de Pedrosa}

El problema de la aprehensión del objeto por los sentidos, según Pedrosa (1995[1949]), es el primer problema del conocimiento humano. En el hecho de percibir las cosas están reunidas explicaciones científicas, filosóficas y estéticas.

Básicamente la aprehensión de un objeto por la vista consiste en distinguir allí una determinada estructura. Hay una experiencia inmediata del mundo que se ofrece al sujeto para ser para ser percibida. Desde que el ser humano nace es capaz de distinguir una forma, por ejemplo, un punto luminoso en la oscuridad. Esta distinción es evidencia de que para él, el mundo inicial no es puro caos sino que se presenta como un campo delimitado sobre el que se destaca una figura. Nuestros ojos, nuestros sentidos segregan los objetos que nos estimulan de acuerdo con un patrón, una organización mediata o inmediata. Un proceso fisiológico resultante de un conjunto de excitaciones tiende a organizarse espontáneamente, más allá de cualquier conocimiento, conforme con ciertas leyes de la estructura. De ese modo, esta primera impresión o modo súbito e instantáneo de conocer es lo que los psicólogos han dado en llamar percepción sincrética global.

Según Koffka (1940), las impresiones primeras de las cosas constituyen las bases de la impresión estética. El arte se funda sobre ellas y pierde su fuerza expresiva, su pureza, cuando esa percepción sincrética global (sentimiento primero del objeto) se marea o tambalea. Eso se produce cuando el arte se mezcla con preocupaciones analíticas o de significación como las exigencias externas, didácticas, científicas, intelectuales, morales, religiosas, prácticas, etc. Cuando eso sucede, el arte deja de ser un fin para convertirse en un medio.

Paul Guillaume (1878-1962), referente de la Gestalttheorie en Francia, señalaba en su Manuel de Psychologie (1943) que la percepción estética frecuentemente respetaba o intentaba reencontrar esas impresiones sincréticas globales. Pero según Pedrosa (1995 [1949]), Guillaume solo presentaba el problema y no formulaba esa 
tendencia en términos de una constancia específica del arte. Si la percepción perdía esas impresiones globales era porque se había perdido en preocupaciones extrínsecas a su propia naturaleza, sirviéndose de procesos como los analíticos, que si bien eran ajenos, se tornaban indispensables cuando se trataba de objetivos prácticos inmediatos o científicos. Era ese análisis el que cortaba y disecaba la impresión al destruir las cualidades sensibles que nos brindan el conocimiento primero del objeto. Entonces, esa característica sensorial pura de la percepción estética indicaba que el problema fundamental, cuando se abordaba el hecho artístico, no era saber cómo los objetos son concebidos en la conciencia reflexiva, sino cómo los percibimos. Lo que seducía al artista era ante todo el aspecto sensible.

La Gestalttheorie según Guillaume (1986 [1947]), procuraba comprender la posibilidad del acto en la psicología funcional. Conectaba, por medio de una causalidad física inteligible, a las propiedades generales del organismo y la acción específica de un excitante complejo. Opuesta a esta, la teoría de Lipps de la Einfühlung (empatía) consideraba que el acto era manifiesto en el sentido del creador, del artista. Todo partía de nosotros, de nuestras emociones y movimientos, siendo la emoción estética una cuestión subjetiva. El objeto era totalmente pasivo y se incurría en un subjetivismo extremo que para la Gestalttheorie significaba una deficiencia de la psicología funcional.

Pero esta teoría no era la única con la que Pedrosa (1995 [1949]) discutía; tampoco acordaba con el filósofo italiano Eugenio Rignano (1870-1930) que limitaba la percepción a una función utilitaria al servicio de la adaptación biológica. Pedrosa recuperaba los debates de la época y mostraba la respuesta al planteo de Rignano que publicó Köhler en el año 1928 en "Bemerkungen zur Gestalttheorie” (Observaciones sobre la teoría de la Gestalt). Köhler aceptaba cierta armonía general entre percepción y necesidad considerándola como expresión de la adaptación biológica; no obstante, ofrecía algunos argumentos para mostrar que no podía explicarse la organización perceptual por la influencia de condiciones afectivas o de los intereses. La segregación de los todos, la impresión global, se daba también relativamente en cosas que no podían definirse como actividades pragmáticas del ser humano o no estaban vinculadas con sus necesidades en términos de brindarle satisfacción (por ejemplo, la 
percepción de una constelación en el cielo no podía ser explicada por necesidades prácticas).

Si ciertas formas nos recordaban las formas de los objetos más directamente ligados a nuestra actividad práctica, era una consecuencia, un efecto y no una causa de su organización formal. En una noche clara, nuestra percepción destaca algunas constelaciones que se agrupan y se delimitan por su contorno; sin embargo, el significado -la constelación de Escorpio, por ejemplo- no explica la agrupación de tales estrellas y no otras, vistas como un grupo aparte. La percepción estética, en gran medida, estaba regida por leyes de organización, de una manera aparentemente desinteresada. Rignano al contrario veía la unidad de una melodía en el sentimiento que la inspiraba y no en sus cualidades formales.

Una persona puede ver algunas manchas de color dispuestas irregularmente como una organización formal autónoma que obedece a leyes de estructura gracias a la variación de colores y de su distribución; esto para Pedrosa (1995 [1949]) no podía explicarse por los valores afectivos ni por la significación adquirida. Entonces, era necesario entender cómo más allá de la significación, en la percepción había ciertos procesos que segregaban las cosas en el espacio y a su vez, agrupaban esas cosas en función de ciertas semejanzas. Uno de esos procesos, la ley de segregación, definía como factor estructural la distancia y la semejanza entre partes como lo que producía agrupamientos (por ejemplo una serie de puntos que tienden a ser percibidos como una línea). A la vez, lo que predominaba en estos agrupamientos era la tendencia a la realización de la mejor prolongación o la continuación del mejor movimiento posibles. Para la Gestalttheorie existía un conjunto de leyes que eran entendidas como combinaciones espontáneas en el plano sensorial perceptivo y que estaban presentes en el ser humano desde el nacimiento. Estas eran las mismas leyes que, empírica e intuitivamente, los artistas habían desarrollado y empleaban desde los inicios del fenómeno artístico (PEDROSA, 1995 [1949]).

Pedrosa (1995 [1949]) sostenía que esas leyes de la psicología constituían un gran principio de la morfología que era indiscutible en las teorías estéticas y en las artes plásticas del momento. Las investigaciones realizadas en el campo de la Gestalttheorie no podían ser más provechosas para el arquitecto, el pintor o el escultor 
que construían para lograr ciertos efectos, basados en esos aspectos del mundo de la visión (distancia, semejanza, buena forma). En el marco de la teoría alemana, la percepción no era fruto, como en el asociacionismo, de la actividad intelectual. El poder de cohesión dentro de toda unidad estructural, de todo complejo figural, se ejercía interiormente, gracias a fuerzas dinámicas autónomas que se manifestaban por la "dialéctica" (sic) del todo y de las partes en el integradas y a él subordinadas (PEDROSA, 1995 [1949]).

En la psicología y en el arte: la buena forma por doquier:

\begin{abstract}
A percepção não nasce, assim, da necessidade de disciplinar dados caóticos descarregados atabalhoadamente sobre nossos sentidos por experiência anterior, preliminar a percepção. A organização percepcional não se compara a um chamado urgente à polícia para dominar a desordem. O mesmo princípio formal encontra-se na física, em que suas leis se manifestam em muitos fenômenos, como mostrou Köhler (PEDROSA, 1995 [1949], p. 116).
\end{abstract}

Como muestra esta cita, el concepto de forma podía aplicarse más allá de los límites de los campos sensoriales. En el arte como en la psicología, las exigencias de la buena forma estaban presentes. Para Pedrosa (1995 [1949]) la creación artística consistía en segregar un todo material o imaginario; el artista decidía cuál de sus partes quedaban, determinaba las posiciones de las mismas y a su vez recibía de estas las irradiaciones o las presiones necesarias para que el todo fuese dotado de su cualidad vital. En ese proceso también se cumplía la premisa de la Gestalttheorie de un máximo de simplicidad y un mínimo de energía en la conformación de la totalidad. El arte era un fenómeno en sí mismo, con sus leyes internas, su autonomía, su escala intrínseca de valores y su poder emocional derivado de su propio drama formal.

Gracias a los desarrollos de las teorías psicológicas de esos años, para Pedrosa, la autonomía de la obra de arte podía justificarse científicamente. El arte como actividad esencial del ser humano, perdía de ese modo su complejo de inferioridad y pasaba a estar en pie de igualdad con otras actividades humanas como la ciencia, la religión o la política. A partir de la Gestalttheorie, Pedrosa destacaba la importancia de considerar los problemas fenomenológicos asociados a la actividad artística, sin olvidar la independencia de la forma en la obra de arte ni entregarse a un subjetivismo abstracto e intelectual basado en el atomismo asociacionista del siglo XIX. 


\section{La figura-fondo según Pedrosa}

Pedrosa (1995 [1949]) planteaba que el ser humano solo percibe a través de diferenciaciones y tomaba de Guillaume los experimentos de Metzger sobre el campo homogéneo y su percepción. La experiencias de Metzger descriptas en "Optische Untersuchungen am Ganzfeld" (1930) y el libro Gesetze des Sehens (1936) consistían en colocar sujetos delante de una gran pantalla blanca débilmente iluminada por un proyector que llenaba todo el campo visual. De esta manera, la pantalla no era vista como una superficie localizada a cierta profundidad. El color parecía llenar el espacio por completo y parecía que se condensaba si se aumentaba la intensidad luminosa del proyector. Ahora bien, cuando la intensidad aumentaba más todavía, la impresión de superficie se precisaba al mismo tiempo que la de distancia. La explicación del fenómeno consistía en que había un progreso de la percepción al diferenciarse en un comienzo la textura superficial del papel de la pantalla, es decir, se hacía visible la trama del papel. Además se concluía que no era posible la percepción del objeto si no existían diferencias de intensidad entre las excitaciones provenientes de varias partes del campo (GUILLAUME, 1984 [1937]).

En una obra pictórica, la posibilidad de establecer una diferenciación de superficie generaba una sensación de espacio. De este modo, un diseño tipográfico, garabatos en un papel, puntos de color en una tela, juegos de luz, manipulaciones lineales se expresaban espacialmente:

\footnotetext{
A superfície de um quadro é um mundo espacial vitalizado não só quanto às forças espaciais que agem dentro dele, mas também no sentido de ser o próprio campo, entre esses movimentos, carregados de ação. Os elementos visuais são apenas os pontos focais desse campo; são a energia concentrada. Cor, valor, textura, pontos, linhas e área irradiam diferentes quantidades de energia -e assim cada elemento ou qualidade abrange certo raio no plano do quadro. Todo organismo vivo - de uma planta a um jogo de futebol- é condicionado por uma forma relativamente constante. A imagem plástica por natureza tende a completar sua unidade dinâmica. "O olho pede o completo" dizia Goethe (PEDROSA, 1995 [1949], p. 123).
}

Esa unidad dinámica hacia la que tendía la imagen plástica o cualquier organismo vivo, se explicaba por aquel principio que describía la tendencia a formar 
unidades ópticas del modo más económico posible respecto al medio circundante. En el caso de un cuadro, las unidades no solo vivían sino que crecían dentro de un molde o de un marco de un cuadro y se fundían en un todo vitalizado por el equilibrio dinámico más logrado.

Ahora bien, el campo visual se organizaba siempre a partir dos elementos opuestos: una figura contra un fondo. Toda imagen se presentaba así en ese dualismo dinámico como la unidad de dos contrarios. En este punto de la exposición de sus ideas, Pedrosa apelaba a la filosofía oriental ${ }^{11}$, especialmente a Lao-Tse. Para ello retomaba lo que planteaba el historiador de arte británico Laurence Binyon (1869-1943) en The spirit of Man in Asian Art (1935). Según Binyon los sabios chinos, antes de Cristo, tenían registro del sentimiento de la vitalidad espacial. Mientras "vacío" y "hueco" eran palabras rechazadas en la mentalidad occidental, Lao-Tse era partidario de la idea de espacio como vacío. Al modelarse un vaso en barro, su utilidad dependía de su interior hueco. Para hacer una casa se abren puertas y ventanas: su utilidad dependía por ende, de los espacios vacíos. De este modo, Pedrosa destacaba que lo inexistente, lo que no estaba -en fin, el vacío- era lo que le daba utilidad a las cosas.

A propósito de las propiedades de los contornos de la cosas percibidas y las relaciones figuras-fondo, otro de los temas que Pedrosa (1995 [1949]) abordaba eran las experiencias sobre la inversión óptica de Erich von Hornbostel (1877-1935) (véase "Über optische Inversion” de 1922). A partir de las mismas concluía que la convexidad y la concavidad eran propiedades "totales"12.

\footnotetext{
${ }^{11}$ La filosofía oriental y sus relaciones con el arte occidental es un tópico recurrente a lo largo de la historia del arte. A propósito de nuestro tema señalamos el debate de Bodenwijnse et al.(2012) sobre las relaciones entre la Gestalt y la Bauhaus y las ideas del artista Tomás Maldonado (1997 [1951]) quien sostenía que ocupar el vacío era fácil (arte tradicional): "la dificultad empieza -es la dificultad del arte concreto- cuando con sutiles elementos queremos organizar estéticamente el vacío" (p. 79. El destacado es nuestro).

${ }^{12}$ Para tal demostración, Hartmann (1935) diseñó un experimento en el que algunos modelos de alambre de figuras sólidas eran sostenidos ante un espejo en varias posiciones. Cuando una figura de este tipo se giraba en diferentes planos, se "caía" de una forma aparente a otra, semejante a las inversiones figura-fondo, salvo que con un objeto tridimensional se abrían más posibilidades. La figura utilizada, por ejemplo, podía aprehenderse mínimamente de cuatro maneras. Cuando ocurrían las inversiones, estas se daban como un solo movimiento completo y unificado: una parte no se "inclinaba" y luego otra, y así sucesivamente. A su vez estas inversiones cuasi sólidas no eran "construcciones" ilusorias ni ideacionales, sino cosas que el sujeto era capaz de percibir en condiciones especiales. Las propiedades fenomenales de una percepción "convexa" eran típicamente distintas de una "cóncava". Lo convexo se
} 
Luego de exponer estas experiencias sobre la figura y el fondo y las propiedades de los contornos, Pedrosa (1995 [1949]) abordaba la cuestión de la unidad espacial en la pintura. En ese contexto, señalaba primero la diferencia entre la vida y un cuadro. En un cuadro, las fuerzas espaciales se equilibraban entre un fondo y un centro. En cambio, para percibir la vida o el movimiento, no teníamos un fondo contra el cual los objetos se moviesen. Dentro de un cuadro pictórico, la construcción de un edificio, delante de una batalla o en presencia de una estatua, las leyes de la unidad dinámica imponían su orden.

La unidad espacial se daba dentro del plano dimensional de una pintura o del plano tridimensional de una escultura o en el plano temporal de la música. En el caso de la pintura, el movimiento lineal en la superficie de un cuadro era un organizador de las formas planas. Los contornos dentro de un cuadro tenían un rol clave en la dirección del curso visual. Cada patrón o figura estaba dotado de individualidad. No obstante, sus contornos tenían maneras propias de actuar; eran en cierta forma inquietos y generaban movimientos en la percepción que organizaban simultáneamente los primeros sub-todos. Es decir, conducían a mirar de un patrón a otro. Del movimiento de esas primeras líneas nacían los primeros sub-todos; de estos, surgían sub-unidades más complejas y así se procesaba dinámicamente la organización total del plano del cuadro. Este proceso de organización a partir de todos de complejidad creciente era para el crítico brasileño una ley de la estructura universal.

Percibir el espacio o la profundidad, era una complicidad perpetuada entre las cosas y el ser humano desde los primeros tiempos. Llenamos los intervalos ópticos con “condescendencia psicológica”. De ellos afloran, como peces del agua, líneas apenas latentes, pero dotadas de las mismas funciones que las cosas semejantes reales:

definía como lo cerrado, excluía al observador, proyectaba hacia delante y no podía ser penetrado visualmente debido a su opacidad ni tampoco manipulado debido a su impenetrabilidad. Así definido, los "objetos visuales" eran convexos. En contraposición, un elemento cóncavo se consideraba como abierto, abarcaba al observador, permitía la exploración visual y manual y poseía las características de un fondo vacío. Los "espacios" eran cóncavos. Todo el proceso de inversión implicaba hacer de algo convexo algo cóncavo y viceversa, aunque por alguna razón, normalmente era más difícil invertir un objeto convexo que uno cóncavo. Los objetos convexos, tomaban por asalto al sujeto e iban hacia él, eran los que más notaba y no ocurría lo mismo con los huecos que se abrían entre ellos (Hartmann, 1935). 
Um quadro é um universo cheio de surpresas. Uma forma, uma estrutura, contém sempre dentro de si os mistérios e os dramas mais inverossímeis. Os intervalos de cores, valores, vivem em estado permanente de disponibilidade, e deles, com freqüência, emergem formas novas até então insuspeitadas. Establece-se mesmo uma hierarquia de metamorfoses, que em sentido descendente produz, dos intervalos de linhas, padrões, e dos intervalos de grupos, linhas. Nessas passagens sucessivas a geração de contornos cinéticos e figuras é incessante, É a lei da clausura em um de seus efeitos mais sutis (PEDROSA, 1995 [1949], P 132).

Por lo tanto, la dinámica lineal se fundaba en la actividad de las líneas reales y en los contornos existentes de las figuras, pero también se apoyaba en los contornos latentes de los intervalos, en la dialéctica de lo cóncavo y lo convexo que mediaba en las figuras. El fondo se tornaba en algo atractivo en términos psíquicos-sensoriales, los "vacíos" y los "llenos" se articulaban en la unidad espacial dinámica. De esta forma, el espacio que se veía entre las cosas no era un vacío sin forma. Hornbostel lo había advertido al decir: "Vemos las cosas, no vemos los agujeros que las separan" (HORNBOSTEL apud GUILLAUME, 1984 [1937], p. 65).

Los planteos de Pedrosa referidos a la forma y la significación provenían de las ideas de Koffka y Rubin acerca del fondo como sustancia (cuya particularidad es tener un grado menor de estructura) y la figura como cosa. La pregunta que orientaba la indagación de Pedrosa era a qué obedecía la fragmentación jerárquica del campo sensorial en términos de figura-fondo. En una nota al pie de su tesis, señalaba que esa misma diferenciación figura-fondo que preocupaba a los psicólogos de la Gestalttheorie era de sumo interés (y anterior en términos cronológicos) en la historia del arte. Pedrosa (1995 [1949]) argumentaba que los conceptos puramente estéticos pertenecientes a la historia del arte podían encuadrarse en esa diferenciación hecha también por la psicología. Recordemos que para los artistas concretos argentinos la relación figura-fondo también era objeto de cuestionamiento hasta el punto de pretender su abolición en la pintura concreta (MALDONADO, 1948; GRASSI, 2019).

En el ámbito de la historia del arte, un caso de abordaje de la relación figurafondo era la apelación de Wölfflin a imágenes semejantes a las utilizadas en la psicología posteriormente en el siglo XX para la distinción de la figura y el fondo con el fin de explicar la diferencia entre lo clásico y lo barroco. Para Wölfflin, la esencia de esta diferenciación radicaba en que era un fenómeno elemental y comparaba su 
variación a lo largo del tiempo, con el espectáculo de una vasija con agua hirviendo. Antes o después de la ebullición, el elemento agua no cambiaba. Lo único que cambiaba era que pasaba de calmo a movedizo, de perceptible a imperceptible. Análogamente, en la historia del arte había existido hegemonía figural en el estilo clásico y predominancia del fondo, durante el barroco pero de alguna forma, el elemento no cambiaba en su "esencia”, sino en su “estado". Para Pedrosa (1995 [1949]), la relación de la figura y el fondo y cómo un estilo privilegiaba a la primera o al segundo, le permitían a Wölfflin trazar una historia del arte. Estos desarrollos habían inspirado a la Gestalttheorie y fueron traducidos a un lenguaje psicológico. Como consecuencia de esta operación, la percepción de la figura y el fondo en la obra de arte (pintura, arquitectura) aportaba al problema de la percepción de la figura y el fondo en el mundo circundante y ampliaba el espectro del problema al redefinir la percepción del mundo en esos términos como hecho psicológico general.

\section{Los valores formales intrínsecos versus la memoria}

A lo largo de su tesis, Pedrosa (1995 [1949]) discutía con la psicología asociacionista al tomar diferentes temas de debate. Para argumentar a favor de la existencia de los valores formales intrínsecos de los todos percibidos, tomaba como contrapunto los desarrollos del filósofo Carl Thusrton basados en aquella psicología, quien en The Structure of Art (1940) afirmaba que muchas veces observamos un cuadro y este posee unidades visuales o relaciones intrínsecas. Ellas se concretan en elementos básicos como las relaciones entre las formas visibles; relaciones entre las formas y el espacio dentro y en torno a ellas; las relaciones entre esas formas y todo el espacio que cae en su esfera y en la del observador y por último, las relaciones desarrolladas en torno al observador en contacto con la obra de arte. Para Thurston, la relación más básica entre dos unidades visuales era de igualdad: uno de los elementos de la organización formal que, apuntaba Pedrosa, postulaba la Gestalttheorie.

Pedrosa señalaba que de igualdad en igualdad, un proceso terminaba fatalmente en la figura simétrica o en las igualdades que eran completas en sí mismas, es decir, la mejor forma posible. Así Thurston, según Pedrosa (1995 [1949]), estaba 
tentado de formular la ley de la buena forma, pero su concepción asociacionista no le permitía otorgarle al fenómeno su alcance en la profundización del problema de las génesis estructurales en la psicología y en el arte. Solo se conformaba con apelar a las figuras elementales geométricas para demostrar la génesis de la obra de arte y explicar el placer producido por ellas en función de su valor estético. Entonces, si bien Thurston era consciente de la autonomía formal porque reconocía que todo lo creado por el equilibrio era inmanente en todas sus partes y aceptaba que si la mayor parte de un área fuese destruida, el pedazo que quedara podría reconocerse como parte de un equilibrio, caía en un equívoco intelectualista. A pesar de todos los principios estructurales que desarrollaba, caía en la trampa de la pregunta acerca del papel de la experiencia previa. Cuando un artista conseguía finalmente transformar el espacio vacío en una parte integrante de su deseo, ¿hacia dónde dirigía su atención? La respuesta era: a su memoria ¿Por qué? Porque el espacio en las artes no se veía de una sola vez. Cuando estábamos frente a un cuadro, durante 5 o 10 minutos, lo que veíamos en ese momento dependía en gran escala de lo que habíamos visto allí antes.

Entonces, para Thurston, la memoria era la que decidía. Cuando el sujeto estaba frente a un cuadro no era capaz de descubrir algo novedoso; la apreciación artística era simplemente una evocación de imágenes vistas. No se trataba de una nueva relación con el universo, ni de una nueva vida: simplemente era una identificación de nuestra memoria con hechos, cosas o experiencias pasadas. Somos “virtuosos del reconocimiento" (THURSTON apud PEDROSA, 1995 [1949], p. 140. La traducción es nuestra). El sujeto no creaba nada, la virtuosidad era la fuerza de la persistencia y de la repetición.

Para Pedrosa, en cambio, percibir era crear y no solo participaba la visión en esa experiencia. Era preciso ver las formas, no con lo que se sabe sino con los sentidos. Los ojos, el movimiento y el tacto participaban de la visión y la inteligencia constituía un factor secundario, inclusive perjudicial, sobre todo en el arte.

\section{La obra de arte como campo de estudio}

La Gestaltheorie partía de la existencia de formas primitivas y postulaba la 
existencia de una disociación entre la figura y el fondo dependiente de cualidades espontáneas e intrínsecas. La percepción se organizaba en función de la influencia de la uniformidad del color o de la luz, la semejanza de los elementos, la solidaridad interna entre los componentes y del ritmo en su distribución. La forma en que se realizaba la percepción siempre era la mejor, o sea, la más regular y la más simple. Se trataba de un sistema que tenía ley propia: su dinámica interior. Por eso esta psicología afirmaba que la percepción no nacía de un caos al que se le imponía orden gracias al auxilio de experiencias anteriores, ni era el resultado de la actividad intelectual.

La percepción primitiva poseía una capacidad intrínseca de organizarse estructuralmente de la mejor manera posible en las condiciones dadas. Por tal motivo, Koffka designaba a la percepción primaria como fuente de la percepción artística. En los orígenes del desarrollo, la primera era idéntica a las primeras reacciones estéticas. Pero entonces Pedrosa se preguntaba ¿por qué necesitamos del arte si la percepción ya es artística? (1995 [1949]). Koffka (1940) respondía que los estímulos ordinarios eran temporarios, el organismo hacía lo mejor que podía en ciertas condiciones, pero en general esas condiciones no le permitían hacer un buen trabajo, artísticamente hablando. Pero una obra de arte era realizada precisamente con el objetivo de, una vez terminada, servir de fuente de estímulos seleccionados específicamente por sus efectos:

\footnotetext{
Assim, a arte seria uma espécie de correção individual, consciente, da percepção primeira, no sentido de lhe dar uma estrutura idealmente perfeita. É um retificador consciente mas desinteressado da percepção, respeitoso porém de sua autêntica espontaneidade primeira (PEDROSA, 1995 [1949], p 148).
}

A través de su estructura, de la vida cualitativa y funcional interior, las formas de los objetos sensibles se presentaban como unidades segregadas. Ciertos objetos tenían el poder de afectarnos directamente, es decir, actuar sobre nosotros mismos. De esta manera, el sujeto y el objeto entraban en una relación directa, espontánea, sintética y afectiva.

La psicología moderna derivaba algunos de sus conceptos explicativos más importantes de las cualidades perceptivas. Pedrosa retomaba aquí la distinción que 
Koffka hizo en "Problems in Psychology of Art" (1940) cuando decía que la obra de arte como un objeto fenoménico del presente constituía un todo que poseía ciertas cualidades. La obra como objeto fenoménico era redondo, anguloso, simétrico, abierto y todos esos aspectos pertenecían a todos completos. También había cualidades como rápido, lento, áspero, liso, gracioso, torpe. Todas ellas eran cualidades de orden temporal o espacio-temporal. Por último, estaban las cualidades como alegre, fulgurante, radiante, sombrío que eran las cualidades terciarias o fisonómicas (que mencionamos en la Introducción). Pero ¿cómo explicar los ejemplos de este último grupo de cualidades?

En primer lugar Pedrosa (1995 [1949]) realizaba una aclaración respecto del método de la investigación. Sus propósitos apuntaban a la obra de arte en tanto objeto que existía independientemente, con sus cualidades intrínsecas y sus propiedades formales que la distinguían como un todo aparte. Por esa razón, para él, el trabajo de Koffka resultaba esclarecedor en lo metodológico. Para resolver el problema de la obra de arte Koffka se preguntaba por la necesidad de hacer foco en el proceso del creador y sus estados anímicos, o en el espectador ¿Cambiará esencialmente una experiencia de oír un scherzo de Beethoven si el oyente está en un estado irascible o triste? ¿No se trataba de escuchar un scherzo de cualquier manera? Para Koffka lo esencial para el psicólogo, era eso último, en tanto entendía el término esencial en el sentido de hacer de la experiencia, una experiencia de arte.

Lo que debía importarle entonces a la psicología era la obra de arte entendida como fenomenológicamente objetiva y funcionalmente subjetiva (el destacado es nuestro). La Gestalttheorie poseía la virtud de abordar el problema artístico sin caer en el unilateralismo subjetivo. Para Pedrosa (1995 [1949]) la distinción entre subjetivo y objetivo era incompleta; existían grados de objetividad y subjetividad. Desde ese punto de vista, una mesa era objetiva, no dependía del sujeto que la observaba para existir. Subjetivo era por ejemplo el sentimiento de miedo, o el dolor que podía sentirse ya que sucedía en la interioridad del sujeto.

Pero en el caso de los colores y los sonidos ocurría algo peculiar. Ambos eran clasificados como subjetivos porque dependían de los organismos para ser percibidos, mientras que la luz y las ondas entraban en la categoría de objetivo. Aparecía aquí otro 
criterio de designación de dos conceptos. Como efecto, los colores y los sonidos eran en un caso subjetivos porque dependían de los organismos, pero también eran objetivos cuando los hallábamos en los objetos (luz y ondas). Según este último sentido, los colores de los objetos estaban en la misma categoría de una mesa, una flor. En ese sentido, se trataba de los colores de objetos.

Cuando se observaba el color marrón de un sombrero o el azul de las tapas de un libro estos no eran del sujeto, así como tampoco ni el sombrero ni el libro. Por lo tanto, según esta clasificación, eran categorías objetivas porque existían con independencia del sujeto; pero también eran subjetivas en otro sentido. En la medida en que se tomaba conocimiento de los objetos coloridos (el sombrero marrón o las tapas azules del libro), eran subjetivos pues dependían del funcionamiento de nuestro sistema nervioso. Sin embargo, nadie podría negar su carácter objetivo ya que ninguno precisaba de un sujeto para continuar existiendo.

De todas esas elaboraciones se desprendía que había dos categorías de subjetivo y dos categorías de objetivo. Según la primera definición, había cosas o cualidades que se clasifican como pertenecientes o no al sujeto. En una segunda definición, las cualidades se dividen en subjetivas porque dependen del organismo y objetivas porque no dependen de él. Toda vez que un objeto entraba en la primera definición, fuese como subjetivo u objetivo (conforme pertenezca o no al sujeto), también necesariamente entraba en una segunda definición, pero esta vez apenas en la categoría subjetiva (la segunda definición clasifica objetividad y subjetividad, según dependa o no del organismo). El dolor, por ejemplo, pertenecía a la categoría de subjetivo en los dos casos (pertenece al sujeto y depende del organismo). Un color, sin embargo, entraba en la categoría de objetivo de la primera definición, pero también en la categoría de subjetivo de la segunda definición porque cuando el organismo toma conocimiento de él, depende del sistema nervioso de ese organismo. Una mesa entraba en la columna de objetivo de la primera definición (no depende del sujeto para existir), en la columna de subjetivo de la segunda definición (existe para el organismo que la percibe), y en la columna de objetivo (no depende del organismo para existir) de esa segunda definición también.

Ahora bien, la mesa era sustituida por la obra de arte, nos encontramos con 
que es fenomenológicamente objetiva (según la primera definición de la dependencia o no del sujeto). Pero de acuerdo con la segunda definición, es funcionalmente subjetiva porque depende, en términos relacionales, del organismo para existir. Entonces la obra de arte pertenecía a la categoría de lo funcionalmente objetivo, que es la característica de lo físico: en donde no hay una mesa, no podemos verla (lo mismo aplica para la obra de arte). Asimismo, un objeto fenoménico era el resultado de la percepción de un objeto físico por parte de un yo.

Los logros de la Gestalttheorie en este campo respondían por el carácter relativamente objetivo de las relaciones formales en el objeto de arte. Esta caracterización de la obra de arte, requería para Pedrosa (1995[1949]) algunas aclaraciones sobre la cuestión de la objetividad y la percepción. Si dos personas veían u oían lo mismo, apreciaban sin embargo, de distinta manera. Era habitual concluir que había una relatividad en ello, pero esto no debía conducir a negar cualquier grado de especificidad intrínseca a la obra de arte. La relatividad real en este caso, consistía simplemente en el hecho de que un objeto fenoménico dependía del organismo individual. Pero esta relatividad era muy distinta de la que suponía que el valor dado o atribuido al mismo objeto dependía de la persona.

Si por un lado la obra de arte como objeto percibido, según las leyes de la percepción, existía gracias a la actividad de un organismo; por otro lado, un organismo era forzado a entrar en actividad por la presencia de una obra de arte, como cosa física. Esta cosa física producía dos polos: en uno estaba su creador y en el otro, su espectador. El objeto realizado era el punto terminal de la acción del artista, pero el punto de partida del espectador también. Aquí era donde se posicionaban las psicologías del arte tradicionales y Pedrosa debatía con psicólogos como Robin George Collingwood, que argumentaba que las obras de arte no eran ni total ni relativamente objetivas. Para el arte y para la estética general afines a estas teorías, no existían las obras, sino solamente las experiencias.

Koffka (1940) reconocía la peculiaridad del objeto de arte (su existencia) y la caracterizaba como la comunicación que se daba a partir una relación establecida entre un espectador y un creador. El punto de referencia de ambos era la obra en tanto cosa, espectador y creador pasaban a existir en función de ésta. Psicológicamente, había un 
sujeto en relación a un objeto en dos sentidos; en un caso, era el artista y la obra creada y en el otro, el espectador y la obra percibida. No se trataba de analizar vía introspección las emociones ocasionadas por la obra para entender su naturaleza o su sentido profundo; esas emociones eran solamente estados producidos por el sujeto. Lo que había que considerar era que esas emociones eran el resultado de la indudable correlación entre el sujeto y ese objeto.

Para Pedrosa (1995 [1949]) la clave de la emoción artística estaba en las propiedades del objeto de arte. Era imperioso considerar la relación funcional de la emoción y el objeto, y que constituía un dato fenomenológico. Justamente, la Gestalttheorie se apoyaba en datos de este tipo para sostener que la relación emocional no era una relación cualquiera, contingente o automática. Ella era un resultado “inteligente” de las propiedades del objeto. En el gozo artístico, esa era la característica vital: la reacción específica, personal e intransferible del yo al llamado de las cualidades propiamente exclusivas del objeto de arte.

Pedrosa recordaba que Koffka en Bases de la evolución psíquica (1926) afirmaba que los estímulos más influyentes en la percepción del niño no eran especialmente los simples. Las primeras reacciones diferenciadas al rostro humano se producían hacia el segundo mes, el bebé recibía el influjo del rostro humano y hacia la mitad del primer año, reaccionaba de manera diferente frente a un rostro "afable" y uno "malo". Lo dado fenomenológicamente era un rostro con tal o cual característica, no un caos de sensaciones. Por ende, fenómenos como "afabilidad o amabilidad" o "rechazo" eran primitivos, inclusive más que una mancha azul o que la distribución amorfa de luz y oscuridad.

Pedrosa recordaba que para Max Scheler, la expresión era lo que primero que el ser humano aprehendía por fuera de él. Así definida, la expresión era la traducción fenomenológica de las primeras estructuras y formas que el bebé recién nacido distingue. Cuando se afirmaba que ciertos fenómenos eran primitivos, no era porque se dividiesen en afectivos y objetivos, ni se yuxtapusiesen; el mundo primitivo como fenómeno implicaba no solo determinaciones afectivas sino también las que se denominaban usualmente objetivas (1995 [1949]).

Entonces ¿por qué afirmar o por qué dudar que hubiese puntos de semejanza, 
trazos comunes, correspondencia entre la forma y la expresión? De las experiencias existentes que revelaban esta relación entre forma expresiva y un fenómeno afectivo, el arte se encontraba tal vez en primer lugar. Entre el sujeto y lo otro, el fenómeno artístico presentaba una mediación incomparable: la obra de arte. Ella estaba dotada de ese poder fisonómico de un rostro que tan bien comprendían el animal y el niño:

\footnotetext{
A forma permite-nos comparar os aspectos sensíveis e fisionômicos das coisas e dos seres. Em arte ela é expressamente o elemento dominador, independente, que obriga os sujeitos a não irem além dela, não atravessarem em busca de elementos extrínsecos, uma intenção prática, um conceito abstrato, a satisfação do interesse, etc. (PEDROSA, 1995 [1949]).
}

Pedrosa (1995 [1949]) no consideraba que las vivencias psíquicas observadas en nosotros mismos a través de la autopercepción fuesen un método adecuado para conocer los sentimientos y las emociones de los otros (empatía). No era cierto que la única asociación o relación existente entre el fenómeno subjetivo y los movimientos de expresión a él subordinados fuera puramente externa. La psicología animal y la infantil con sus investigaciones desmentían ese empirismo. Según estas, no podía explicarse que los animales comprendieran las reacciones de sus compañeros por recurrir a una analogía consigo mismos vía introspección.

Otro de los argumentos a favor de esta idea de soldadura entre forma y expresión, pertenecía a Köhler quien recurría a la frase del poema de Goethe "Epirrhema" (1820) ya mencionada "Denn was innen, das ist außen" (Lo que está adentro, esta también afuera) para explicar el paralelismo entre lo externo y lo interno. Los dos aspectos expresaban un mismo dinamismo psicofísico. Köhler decía que con frecuencia, las partes del cuerpo donde ese dinamismo se expresaba de modo visible eran precisamente aquellas en donde más se sentía. Una primera coincidencia era que el curso temporal del fenómeno subjetivo y la expresión eran paralelos. Una misma curva acompañaba esa evolución, había un crescendo y un decrescendo, una fase estacionaria y fluctuaciones. Era posible describir en el pensamiento de un sujeto conmovido las mismas pulsaciones que en sus reacciones musculares. Los movimientos "secretos" del alma (GUILLAUME, 1986 [1947]) y los movimientos manifiestos u ocultos del cuerpo eran la imagen unos de los otros. 
Un hecho indiscutible era que percibimos realmente cualidades formales de comportamiento y esas propiedades tienen por sí mismas un sentido, un valor, una exigencia interior. De acuerdo con esto, una de las funciones naturales, espontáneas del arte consistía en no permitir el desvío o el ocultamiento del sentido intrínseco emanado directamente de la percepción formal primitiva, desembarazada de todo asociacionismo mecánico y cultural (PEDROSA, 1995 [1949]).

Es interesante destacar aquí cómo se imbrican el hecho de que Pedrosa no adhería a la idea de definir un único lenguaje artístico por sobre otros, con el postulado de universalismo que subyacía a la concepción del sentido o exigencia interior como intrínseco de las formas en la obra de arte. Esta articulación marcaba una diferencia respecto de la cuestión de la prevalencia de un estilo y el universalismo de la forma para los artistas concretos argentinos. Sin embargo, como mostramos al principio de nuestro trabajo, esto no impidió la recepción de las ideas de Pedrosa en el circuito argentino, a pesar incluso de las diferencias en ambos países respecto a las formas específicas de circulación de la Gestalttheorie en el arte concreto que hemos denominado latente (en la Argentina) y manifiesta (en Brasil). Para los argentinos, el estilo concreto era considerado como la culminación de un proceso de evolución en la historia del arte (y por eso mismo, la única tendencia aceptable) y el universalismo de la forma estaba vinculado no exclusivamente a las cuestiones de expresión (más allá del carácter figurativo o no) sino al carácter presentativo o concreto de las formas geométricas empleadas en las obras (MALDONADO, 1997 [1945]).

En síntesis, para Pedrosa las propiedades formales se bastaban a sí mismas. Si nuestras vivencias eran evocadas por el comportamiento de los otros era porque esa evocación se daba en virtud de una comunidad primitiva de estructura. La Gestalttheorie llevaba a pensar en la irreductibilidad expresiva de cada conjunto, ser, cosa o situación y planteaba que:

Os objetos têm por si mesmos, em virtude de sua própria estrutura, independentemente de toda experiência anterior do sujeito que os percebe, um caráter próprio, as qualidades do insólito, do estranho, do assustador, do irritante ou do plácido, do gracioso, do elegante, do áspero, do maravilhoso, do repulsivo, do atraente, etc. (PEDROSA, 1995 [1949] p 163-164). 
El aspecto fisonómico era parte del objeto, estaba en su naturaleza como una consecuencia de su forma. Wertheimer descartaba la tesis de la separación de cuerpo y experiencia o cuerpo y alma, y afirmaba que en la danza se hallaban la gracia y la alegría. No podíamos aislar los movimientos de los miembros por un lado y una experiencia psíquica consciente por el otro. En todo caso, se trataba de una identidad formal.

Para la Einfühlung (empatía) de Lipps, al contrario, las cualidades sensibles eran una proyección del yo. Toda esa "vida" que le otorgamos a las cosas que nos rodean solo puede darse en la medida en que atribuimos a las cosas exteriores nuestro propio sentimiento de fuerza, de lucha o de voluntad. Para esta teoría, la experiencia estética era de origen puramente subjetivo, en el sentido de que pertenecía al yo o al sujeto. Para Pedrosa (1995 [1949]) esta teoría era objetable: si se yergue el brazo delante de la columna dórica, la teoría de la empatía no explica la razón de esos sentimientos o gestos.

Él aportaba a favor de su posición los desarrollos de Naum Gabo, quien no dudaba en atribuir a la existencia misma de la obra de arte todas esas cualidades que nos afectan delante de ella. Pedrosa citaba entonces el texto publicado por el escultor constructivista ruso, aparecido en la revista Circle con el título "Sculpture: Carving and Construction in Space" (1937) en donde planteaba que toda forma que se había tornado "absoluta” adquiría vida propia, hablaba su propia lengua y representaba un único embate emocional atrapado en ella misma. Es decir que para Gabo, las formas actuaban, influenciaban nuestra psique; eran, en sí mismas, acontecimientos y cosas (PEDROSA, 1995 [1949]).

En síntesis, la forma tenía en sí misma una fuerza emocional que era irresistible y universal. De ahí que fuese imposible aprender el contenido de una forma absoluta solamente por medio de la razón. Nuestras emociones eran una verdadera manifestación de ese contenido. Pedrosa (1995 [1949]) afirmaba que esos caracteres terciarios y fisonómicos de los objetos que habían sido un misterio para la psicología, ya no lo eran porque se había llegado a la conclusión de que eran cualidades inherentes al objeto fenomenal. Nuestra tarea consistía en consentir y verificar la presencia de esas cualidades terciarias donde las veíamos: en otro sujeto, en un 
triángulo, en una columna egipcia, en una palma ornamental, en definitiva, en un todo cualquiera segregado. En esas condiciones, no estaba del todo mal admitir los ingenuos planteos de la teoría de la empatía de Lipps que atribuían la cualidad de esa misma cosa a la acción que esa cosa ejercía sobre nosotros. Pero los artistas modernos, en este punto daban un testimonio para nada despreciable. No era propiedad exclusiva de los artistas sentir los efectos de las cualidades terciarias, sino que en la apreciación de una obra de arte, todo el mundo era artista, pues debía colocarse en el mismo plano que este para apreciarla ${ }^{13}$.

La afirmación de que todo el mundo era artista es interesante ponerla en diálogo con la aspiración de un arte para todos, propia del concretismo argentino. Es decir, con la apuesta política de que todos podían apreciar el arte abstracto porque la significación estaba en la forma, razón por la que no había que ser ni erudito ni especialista (MALDONADO, 1951). El hecho de prescindir del capital cultural del espectador o de la memoria como función psíquica participante, ampliaba considerablemente el público del arte tanto para Pedrosa como para los argentinos ${ }^{14}$.

Pero ¿cómo explicar el proceso de fabricación de cualidades terciarias artísticas? Este era en sí un tema difícil de elucidar para Pedrosa. Para hacerlo, proponía centrarse en algo más preciso y concreto: las relaciones del sujeto y del objeto (la obra de arte concretamente), y de ambos con el mundo. El objeto, cuando estaba en el mismo campo que el sujeto, lo tocaba emocionalmente por sus cualidades intrínsecas. Todo pasaba a ser en el plano de las emociones y los sentimientos. Sin embargo, el campo que los envolvía variaba de caso en caso e iba desde la integración hasta la oposición del sujeto respecto al objeto en ese campo. En este punto, en la tesis de Pedrosa se retomaban cuestiones acerca del contexto histórico social del surgimiento de la Gestalttheorie (véase Grassi, 2019). Básicamente se remontaba a los desarrollos de Koffka en lo relativo al problema de la diferenciación, la fragmentación y el aislamiento del sujeto concomitante con el progreso de la civilización. A raíz de esto,

\footnotetext{
${ }^{13}$ No obstante, puede pasar que no toda obra de arte nos emocione, pero es debido a otras razones. Las cualidades terciarias inherentes a todo objeto fenomenal no son todas de orden artístico. Pero la función del artista consiste precisamente en fabricarlas.

14 Téngase en cuenta también la inclusión por parte de Pedrosa del arte producido por pacientes psiquiátricos y sus interesantes elaboraciones al respecto. Puede consultarse sobre el tema Learning from Madness (2018) de K. Cabanas.
} 
el mundo de esos años era más pobre en caracteres fisonómicos comparado con las civilizaciones primitivas. Nuestra civilización utilitaria había lanzado un importante descrédito sobre las propiedades fisonómicas, estructurales de los objetos. Pero el arte era el modo específico de las más puras y desinteresadas de esas cualidades de las cosas. Esta diferencia había mutado en una incompatibilidad entre el sistema racional y científico por un lado, y el sistema cualitativo dominante en la estética por el otro (PEDROSA 1995 [1949]).

Finalmente, Pedrosa cerraba su tesis con la idea de que el acto de percibir era un acto de creación. La forma perceptual obedecía, en lo rudimentario de su organización, a las mismas leyes de la buena forma que regían el mundo y la obra de arte. Esta idea aparecería unos años después (en 1954) en el libro de Arnheim Arte y percepción visual. Psicología de la visión creadora. Para muchos, esta obra era el primer intento de aplicar las leyes de la Gestalttheorie al arte visual (Herbert Read creía esto, por ejemplo). Sin embargo, Pedrosa ya había presentado su original tesis en Río de Janeiro e incluso Arnheim había publicado antes un libro sobre cine (ARNHEIM, 1933).

No obstante, aún cuando haya considerado desarrollos teóricos sobre el arte de la Gestalttheorie (tal es el caso del artículo de 1940 de Koffka "The problems of the Psychology of Art" para hablar de las propiedades fisonómicas), la propuesta teórica y metodológica del crítico brasilero, constituyó un aporte tanto para el arte como para la psicología al lograr articular ambos y dar respuesta a planteos cruciales como la significación, la expresión y aspecto relacional de la apreciación artística a partir de considerar a la obra como un objeto fenomenológico.

\section{Reflexiones finales}

Hasta aquí hemos analizado la propuesta teórico-metodológica de Pedrosa retomando algunos núcleos de Forma e personalidade vinculados con la Gestalttheorie centrados en su obra más importante sobre la Gestalttheorie que fue Da natureza afetiva... Algunos de estos núcleos como la noción de totalidad, el papel de la percepción entendida como acto inteligente y creador y la importancia de la forma y la tendencia a la configuración reaparecen de manera abreviada en dos artículos suyos 
publicados en revistas culturales argentinas y dan cuenta del "ideario Pedrosa" que circuló entre los artistas concretos argentinos quienes, a su vez, escribieron textos y crearon sus obras en el marco de una variedad de discursos científicos y estéticos. Mencionamos en el caso argentino, la "latencia" de la Gestalttheorie -manifiesta en la cuestión de la citabilidad- que no ponderamos como un déficit o una falta de rigor ya que eso significaría confundir regímenes científicos de circulación epistémica con lo que denominamos regímenes estéticos de circulación epistémica. Consideramos que señalar esto simplemente contribuye a pensar la diferencia en la modalidad de circulación de la teoría respecto al caso del arte abstracto brasileño.

La investigación de Pedrosa fue una de las vías de la psicologización del estudio de la forma y el color a través de la articulación Gestalttheorie-arte que destacó el carácter expresivo de la forma. Si bien este último no constituyó el argumento más fuerte de los concretos argentinos para justificar el carácter universalista de su propuesta estética (estaban volcados a una concepción más racionalista), Pedrosa estuvo presente y fue un autor que circuló en el ámbito argentino. Queda pendiente analizar la circulación a nivel internacional que lograron este texto y otros elaborados en aquellos años. Un análisis futuro más detallado, permitirá situar mejor la originalidad de Pedrosa y la innovación que supuso su enfoque respecto a los desarrollos de Arnheim sobre arte y Gestalttheorie mundialmente conocidos. Para ello, será necesario cuestionar la mainstream de la historia de la psicología y dejar que las "periferias" nos sorprendan como lo hizo Pedrosa con sus desarrollos en aquellos años.

\section{Referencias}

ARANTES, O.B.F. (1995). Prefácio: Mário Pedrosa, um capítulo brasileiro da teoria da abstração. In: Forma e Percepção Estética. Textos Escolhidos II. San Pablo: Editora da Universidade de São Paulo. 1995. p. 13-38.

ARNHEIM, R. Film. London: Faber \& Faber. 1933.

BINYON, L. The Spirit of Man in Asia Art: Being the Charles Eliot Norton Lectures Delivered in Harvard University, Cambridge: The Harvard University Press. 1935.

CABANAS, K. Learning from Madness. Brazilian modernism and Global 
Contemporary Art. Chicago y Londres: The University of Chicago Press Chicago and London. 2018.

GARCÍA, M. A. Prati, pionera de la abstracción argentina. Diario Página 12. 25 de agosto de 2009. Disponível em: https://www.pagina12.com.ar/diario/suplementos/espectaculos/6-15051-2009-o825.html

El arte abstracto. Intercambios culturales entre Argentina y Brasil. Buenos Aires: Siglo XXI. 2011.

GOETHE, W. Ephirrema. Recuperado de: https://www.textlog.de/18635.html. 1820.

GRASSI, M. C. Arte abstracto y psicología de la Gestalt en la Argentina. Una historia de la psicologización del estudio de la forma y el color (1944-1953) (Tesis doctoral). Facultad de Psicología de la UNLP, Ensenada. 2019. Disponível em: $<$ http://sedici.unlp.edu.ar/handle/10915/77425>.

GUILLAUME, P. Psicología de la forma. Buenos Aires: Psique. 1986 [1947].

HARTMANN, G. W. Gestalt Psychology: A Survey of facts and principles. New York: The Ronald Press Company. 1935.

KOFFKA, K. Bases de la evolución psíquica: Introducción a la psicología infantil. Madrid: Revista de Occidente. 1926.

Problems in the psychology of art. En R. Bernheimer, R. Carpenter, K. Koffka, \& M. C. Nahm (Eds.), ART: A Bryn Mawr Symposium (Vol. IX, pp. 180-273). New York: Sentry Press. 1940.

MALDONADO, T. El arte concreto y el problema de lo ilimitado. Notas para un estudio teórico. Material cedido por Yale University Art Gallery (17/11/2015) (1948).

. Respuesta ¿A dónde va la pintura?, Contrapunto, n³, Buenos Aires, 3 de abril. En T. Maldonado, Escritos preulmianos. Buenos Aires: Ediciones Infinito. p. 35-36. $1997[1945]$.

Actualidad y Porvenir del Arte Concreto. En T. Maldonado, Escritos preulmianos (71-80). Buenos Aires: Ediciones Infinito. 1997 [1951].

PEDROSA, M. Calder y la música de los ritmos visuales. Ver y Estimar: revista de crítica artística, 9(31), 5-24. Recuperado de Revistas de Arte Latinoamericano, Disponível em: <http://www.revistasdeartelatinoamericano.org/items/show/86.1953>. Acesso em: 3 jan. 2021. 
(1955). Las relaciones entre la ciencia y el arte. Nueva visión: Revista de cultura visual, 6, 14-17. Recuperado de: Revistas de Arte Latinoamericano, Disponível em: <http://revistasdeartelatinoamericano.org/items/show/167>. Acesso em: 8 set. 2020 .

Da naturaleza Afetiva da forma na obra de arte. In: O.B.F. Arantes. Forma e Percepção Estética. Textos Escolhidos II. San Pablo: Editora da Universidade de São Paulo. 1995 [1949]). p. 107-177.

Forma e personalidade. In O.B.F. Arantes. Forma e Percepção Estética. Textos Escolhidos II. San Pablo: Editora da Universidade de São Paulo. 1995[1951]. p. 179-220.

De la naturaleza afectiva de la forma. Museo Nacional Centro de Arte Reina Sofía. Catálogo publicado con motivo de la exposición Mário Pedrosa. De la naturaleza afectiva de la forma, organizada por el Museo Nacional Centro de Arte Reina Sofía desde el 28 de abril al 16 de octubre del 2017. 2017

PEREZ-BARREIRO, G. Sensibilizar la inteligencia: una introducción a la crítica de arte de Mário Pedrosa. In: PEDROSA, M. De la naturaleza afectiva de la forma. Madrid: Museo Nacional Centro de Arte Reina Sofía. 2017. p. 14 - 33.

THURSTON, C. The Structure of Art. Chicago: The University of Chicago Press. 1940. 